tympanic membranes was induced by the concussion, and beyond scorching his chest and face no other damage was susainted.

Whilst writing the above another explosion has occurred similar to Case 4, but happily without doing serious injury.

$1 \mathrm{am}$ fully aware that no special point of surgery is illustrated in the narration of these cases, and it is not with that intention that I record them. They are interesting and also instructive, in so far as they show a necessity for the greatest care in the manufacturing and using of such dangerous articles. I might say more on this point, but a medical journal is hardly a suitable medium.

Morro Velho, Brazil.

\section{CASE OF VAGINAL HYSTERECTOMY FOR MALIGNANT DISEASE.}

BX FERDINAND A. PURCELL, M.D., SURGEON TO THE CANCER HOSPITAL.

THE case of extirpation of the uterus and its appendages per vaginam which $I$ have to report makes my fourth successful case. A record of the three previous cases appears in a paper by me, and is published in the British Gyncecological Journal (May, 1887, Part ix., p. 60), and was read before the Society on March 9th of this year. I intend to give a full report of this case to show that I have not, with my additional experience, departed from the plan of operation followed in my first three cases.

We may take it for granted that kolpo-hysterectomy is only justifiable when the body of the uterus is cancerous, or when the disease commences near the os internum; and unjustifiable for cancer of the cervix alone, or when the walls of the vagina have been encroached upon, for in the latter condition the surrounding cellular tissue has already been infiltrated, and recurrence after operation will undoubtedly take place in a very short space of time.

Operators are still divided as to the details of the operation: as to whether the peritoneum should be entered in the anterior fornix or the posterior fornix; whether the fundus is to be brought down through the anterior wound or the posterior one; or not to make the uterus perform a somersault at all, so as to avoid all risk of soiling the peritoneum with the discharges from the diseased os and neck; or whether it is not advisable to remove the diseased cervix as a preliminary operation by amputation or with the curette; whether the broad ligaments should be ligated en masse, or in segments, or to rely on pressure forceps to be left in situ. whether the ovaries ought to be removed; whether the vaginal walls and peritoneal edges should be brought together with suture, or leave the vaginal wound unclosed; and whether a drain is to be used.

Mrs. Eliza $K-$, aged forty-six, was admitted into the Cancer Hospital on June 17th, 1887, being a patient sent to me from Birmingham by Dr. John W. Taylor, who had curetted and cauterised the os and cervix about three months previously at the Birmingham Hospital for Women and where she was at the time examined by Mr. Lawson Tait. The patient is a fairly well-nourished woman, the mother of one child aged twenty-four years, and had always enjoyed good health until about twelve months ago, when she had romiting of blood and violent pains across the pit of the stomach and back. Three months subsequently (Sept. 1886) a raginal discharge cam $\theta$ on, and pain, with difficulty in micturating, necessitated treatment under the care of Dr. John IT. Taylor, and in January he performed an operation on the urethra. Some six weeks later malignant disease of the os and cervix was discovered; for this she was examined, in conjunction with Dr. Taylor, by Mr. Lawson Tait, and had the os and cervix curetted and cauterised by Dr. Taylor. Recurrence of the disease showed itself about three weeks ago, for which Dr. Taylor advised kolpohysterectomy, and kindly sent her to me. The disease now occupies the stump and neck as far up, if not beyond, the os internum; walls of the vagina are sound. On examining with the two fingers in the rectum and the other hand over the pubes, the body is found larger than normal, more particulariy its left half; the organ is freely movable, and the broad ligaments appear healthy; no enlarged glands are to be felt. She has passed the menopause. There is no family history of cancer or of phthisis to be made out. Father died at seventy-nine; mother died at seventy-two, having had thirteen children. After a consultation with my colleagues, and having decided that removal of the uterus was justifiable, fully explaining the nature and risks of the operation to the patient, as also to her husband, and which they had had previously explained to them by Dr. Taylor, consent was given and the best wished for.

On June 23rd I proceeded to operate, assisted by my colleagues, Dr. Snow and Mr. Jessett. Dr. John W. Taylor came up from Birmingham and was present, as also Mr. Henry Reeves, and other visitors. The patient was placed in the lithotomy position, the bladder emptied, and vagina and parts douched with carbolised water; a duck-bill speculum in the posterior fourchette, aided by the fingers of my assistants, brought the parts well into view. Steadying the uterus by fixing a vulsellum in the cervix, the mucous membrane was incised all round, the anterior and posterior flaps reflected upwards, the bladderkept out of the way, and a segment pinched up laterally (first one side then the other), and a ligature passed through it with an aneurysm needle, so as to include the Inwer uterine vessels, was tied, and divided away. The peritoneum was entered both anteriorly and posteriorly, and the apertures enlarged by tearing; the two fingers of the right hand were passed up through the anterior opening and over the fundus, and then over the right broad ligament, which it was made to encircle. Now a silk thread was passed by means of a long well-curved aneurysm needle on the finger, until it encircled the broad ligament and insinuated down posteriorly; the thread was hooked out of the eye and the needle withdrawn; the broad ligament was gently drawn down and examined for absence of ureter. Feeling satisfied of its not being present, the ligature was tied. Tying the broad ligament en masse, close up to the ligature on its uterine side, I applied two pressure forceps as a guard, and, cutting the thread short, divided the parts away from the uterus with scissors. The pedicle receded together with the forceps; the uterus sidled down, presenting its right cornu ; the left-hand fingers now were passed in front and above the left broad ligament, followed by a silk thread, which was passed through the substance double. Having examined for absence of ureter and not observed, it was tied double and again encircled, clamped with pressure forceps and divided. The Fallopian tube was not included, and on bringing the uterus down, which was now free, the left ovary came down along with it, and on gently drawing, the Fallopian tube followed, when all was withdrawn; the Fallopian tube on the right side had been included in the pedicle, but now the right ovary was felt for and brought down, its attachment tied and severed, and it was got away. Parts around and within were douched, cleaned, and dried; there was no oozing of blood, and little blood was lost. The pressure forceps were all carefully taken off; no attempt at closing the vaginal or peritoneal wotind was made. Bladder and bowel and surrounding parts were finally examined, a glass drain, with its end rounded, but perforated, was inserted; this and the vulva was covered up with a large pad of salicylic wool and fixed by a T bandage; patient was removed to her bed in the general ward. The operation from first to last occupied one hour and twenty minutes.

In the evening, after operation, the pad and draw-sheet were found saturated with coloured water. Four ounces of urine were drawn off, and it was ordered to be drawn off by catheter when necessary. Temperature ranged between $96.8^{\circ}$ and $974^{\circ} \mathrm{F}$. The patient partook of ice only.

June 24th.-Patient passed a comfortable night; had no sickness. Five ounces of urine drawn off. Salicylic wool pad dry ; renewed. Iodoform dusted about and up the drainage tube; tube not interfered with. Pulse 74, intermittent; temperature (twenty-four hours) ranged between $98 \cdot 2^{\circ}$ and $100^{\circ} 2^{\circ}$

25th.-Slept at stretches of an hour; comfortable; no sickness. Was given six ounces of barley water during the night, and one drachm of essence of beef given twice; pad dry. Urine free. Temperature (twenty-four hours) ranged between $100^{\circ}$ and $994^{\circ}$.

26th.- - Very comfortable night; slept two hours at a time. Urine drawn off. Pulse feeble and intermittent. Pad dry. The drain taken out for the first time; only a small piece of shred found clung in a couple of the holes; its inner surface is coated with iodoform; no smell; clesned and replaced as before. Diet increased-fish, the essence of beef 
more frequently, barley water, and arrowroot. The temperature during the forenoon was $99.6^{\circ}$; afternoon to midnight it ranged from $100^{\circ}$ to $101 \cdot 4^{\circ}$.

27 th. - Took nourishment well. At 5 A.M. complained of sickness and pain in left iliac. Urine drawn off. Abdomen is tympanitic. Passed some flatus, but with difficulty. Slight discharge found in the glass drain. Applied a turpentine fomentation, which relieved her. The wool pads were more soiled later on. T'emperature for twenty-hours ranged from $99 \cdot 4^{\circ}$ to $101 \cdot 8^{\circ}$.

28th.-Slight pain in left iliac; urine drawn off; pad not much soiled; tube contains pus; taken out and cleaned; was reinserted, and then iodine water was injected through it, bringing away some purulent discharge enough to colour the water. Temperature $996^{\circ}$ to $1018^{\circ}$.

29 th.-Complains of a throbbing pain in urethra; pad slightly soiled. Temperature $996^{\circ}$ to $1024^{\circ}$. To have a turpentine enema; iodine water douches to be continued twice a day.

30th.-Temperature was high all night; rose to $101 \cdot 8^{\circ}$, and in the afternoon from $101 \cdot 8^{\circ}$ to $1024^{\circ}$; enema acted slightly; pad but little soiled. To have a terspoon of oil.

July 1st.-Slept well and taken nourishment. The tube is half full of pus; the syringing with iodine water has been done night and morning regularly. Temperature $1018^{\circ}$, $992^{\circ}$, and $100 \cdot 6^{\circ}$. Bowels acted well.

2nd.-Pulse 66, regular ; eats well ; discharge of pus continues. Temperature $1004^{\circ}$ to $984^{\circ}$.

10th.-Discharge lessened every day. The tube is now removed, and she is permitted to pass urine of herself, and allowed up on the couch. From this she became convalescent and began to walk about. Examined the vagina; found that the two fingers passed up to their full length; the vault is broad, and not at all contracted; the broad ligament pedicles distinctly to be felt. Returns home to Birmingham. Manchester-square, $\mathrm{W}$.

\section{ON A}

\section{METHOD OF DETECTING AND REMOVING NEEDLES EMBEDDED IN THE TISSUES.}

BF H. LITTLEWOOD, F.R.C.S. ENG.,

RESLDENT SURGICAL OFFICER TO THE LEEDS GENERAI INFIRMARY.

I BELIEVE the general advice given by surgeons when a needle becomes embedded in the tissues, if it cannot be felt, is "to let it alone," with the hope that it will either work its way out or become embedded where it will give rise to no trouble; the reason being that the task of removal under these conditions is always very difficult and often impossible-almost like looking for the proverbial needle in the haystack. Having had several such cases, where I could not be actually sure of the presence of the needle, I have gone on the plan of "letting alone"; in two or three cases the patients have come to me several weeks after, bringing the needle, which had worked its way out, they having in the meantime undergone several weeks of pain and mental anxiety. These cases led me to try if it were not possible first to detect the presence of, and then remove, the needle. Since then I have adopted the following plan with considerable success.

1. The part supposed to contain the needle is thoroughly rubbed over with an electro-magnet, so as to magnetise the metal if present. 2. A delicately balanced magnetic needle is held over the part. If the needle is present, its position can be ascertained by the attraction or repulsion of the poles of the magnetic needle. 3. Having ascertained the presence of a needle (e.g., in the hand), the part is rendered bloodless, and a grain or more of cocaine injected hypodermically. 4. An incision is made over the ascertained position of the needle. 5. The electro-magnet is then inserted into the wound, and with it the needle is felt for. Sometimes it will be found and remored quite easily, at others great difficulty will be experienced, taking as long as one-half or threequarters of an hour. This may be due to the fact that its position has not been accurately ascertained; it may be lying across the incision, or it may be so firmly embedded in the tissues that the electro-magnet is not able to withdraw it. If this occurs the incision must be enlarged, and the edges held apart with some non-magnetic retractors; using the electromagnet as a guide, the needie may be seen and remored with forceps. If the needle is firmly fixed, the following plan has been adopted: by placing the positive pole of a galvanic battery on the surface of the body and the negative pole is direct contact with the needle, this becomes loosened ky electrolysis and can then be easily removed by the electromagnet. This latter method has been found useful in two cases for the removal of sewing machine needles that had transfixed the end of the finger, and were so firmly fixed as not to be removable by forceps. The electrolytic action loosened the needles so that they could be removed quite easily.

Mr. Marshall, in his lectures on Surgery at University College, used to tell us that needles \&c. could be detected in the tissues by the method described above. I had not seen it practically tested. After haring removed two or three needles by the method described above, I referred to Neale's Digest to see what had been written on the subject. I find the following references which I think will be of interest:- In the Medical Times and Gazette (vol, i., 1857, p. 298) is a paper by Dr. Bence Jones, entitled "On a ready method of determining the presence, position, depth and length of a Needle broken into the Foot." In the same journal (vol. ii., 1876, page 531) is a paper by Sir Benjamin Brodie, in which the presence of a needle in the leg of his own son was demonstrated at the Royal Institution by means of the electro-magnet. It was not then removed, but allowed to remain in some time, until it worked its way to the skin on the opposite side of the leg, and then removed. Both these papers refer only to the detection of the needle. In THE LANCEI (vol. ii. 1876, p. 700) is a communication by an army surgeon named Thompson describing a case in which he made an incision over the site of a piece of metal embedded, and then bandaged an ordinary magnet over the part for twenty four hours, with the satisfaction of finding the metal attached to the magnet at the end of that time.

I have now removed six needles from the hand and a piece of steel embedded in the foot. In none of the cases could I feel the piece of metal or be sure of its presence without the aid of the method above described. As it requires somo expensive apparatus, and sometimes takes a long time, I am afraid this method will not become general; but it is well worth the time and trouble spent if in the end one is successful; as patients really suffer a good deal of pain and anxiety if these foreign bodies are allowed to remain embedded in the tissues.

\section{ON THE PATHOLOGY OF HEMIPLEGIA.}

BY FRANCIS W. CLARK, L.R.C.P., M.R.C.S., ASSISTANT MIEDICAL OFFTCER TO THE CROYDON INEIRMARY.

As the pathology of certain cases of hemiplegia is still somewhat obscure, I venture to give a brief résumé of some thirteen cases of the disease which have come under my care during the past year, with a view to suggesting that some of these depend, in all probability, upon a chronic pachymeningitis of the vault due either to alcoholism or more rarely to rheumatism.

Of the thirteen cases three were due to massive hæmorrhages into the brain, as verified by post-mortem examination; and hence these cases need not detain us at all.

of the remaining ten cases, in two only were there any evidences of morbus cordis. The first of these-George $\mathrm{K}$ - - aged forty-five-had an attack of right hemiplegia with left facial palsy, from which he recovered to a great extent in the course of a few weeks. Four months later, however, he succumbed to the effects of the morbus cordis but, unfortunately, no necropsy was granted. The crossed paralysis in this case is suggestive of the lodgment of small embolus in the pons Tarolii.

The other case associated with morbus cordis was that of Jesse $\mathrm{Y}-$, aged sixty-eight, who had an attack of left hemiplegia six years ago, from which he recovered in a short time; a second attack, on the same side, four years ago, with recovery; and he is now convalescent from a thirc attack, also on the left side, but this time associated with difficulty of articulation. As there is in this case also a history of alcoholism, 1 shall refer to it again under that head.

In one case only was there a history or any evidences of syphilis-namely, that of a young man (J. P-) aged 